DOI: https://doi.org/10.35699/2238-037X.2019.12299

\title{
(IM) POSSIBILIDADES DE REGULAÇÃO NO TRABALHO EM PROFISSIONAIS DO CENTRO DE MATERIAL ESTERILIZADO (CME) ${ }^{1}$
}
(Im) possibilities of regulation in the work of professionals from the Center of Sterilized Material (CSM)

RODRIGUES, Pedro Luiz C. ${ }^{2}$

MENDES, Davidson Passos ${ }^{3}$

\begin{abstract}
RESUMO
Partindo de uma análise aprofundada sobre a atual situação das relações de trabalho e suas consequências para os atores envolvidos, o presente artigo, por meio da ergonomia e da ergologia, buscou dar visibilidade ao trabalho desenvolvido em um Centro de Materiais Esterilizados (CME), situado em um hospital, e as estratégias ali construídas e necessárias para a gestão do trabalho. Buscou-se demonstrar as diversas atividades inerentes à prática do trabalho, bem como as variabilidades presentes nesse contexto, bem como as diversas estratégias de regulação no trabalho ao almejar dois objetivos principais: 1) manutenção da própria saúde e, 2) eficiência na realização do trabalho. Foi evidenciado que há insuficiência de materiais e equipamentos e que isso impacta diretamente no cotidiano da assistência, na carga de trabalho dos trabalhadores do setor e de outros setores em interface com o CME. Porém, pode-se demonstrar também, que estratégias foram construídas e compartilhada, moduladas pela competência individual/coletiva analisada e que se mostrou de fundamental importância para a gestão da produtividade e dos riscos no contexto analisado.
\end{abstract}

Palavras chave: Estratégias de Regulação. Centro de material esterilizado. Saberes e valores.

\section{Abstract}

Based on an in-depth analysis of the current labor relations situation and its consequences for the actors involved, this article, through ergonomics and ergology, sought to give visibility to the work carried out in a Center for Sterile Materials (CME) in a hospital, and the strategies built there and necessary for work management. It was tried to demonstrate the diverse activities inherent in the work practice, as well as the variabilities present in this context, as well as the various strategies of work regulation, aiming at two main objectives: 1) maintaining one's own health and 2) job. It was evidenced that there is insufficient materials and equipment and that this has a direct impact on daily care, the workload of workers in the sector and other sectors in interface with the CME. However, it can also be demonstrated that strategies were constructed and shared, modulated by the individual / collective competence analyzed and that proved to be of fundamental importance for productivity and risk management in the analyzed context.

Keywords: Regulation strategies. Centro of Sterilized Material. Services and values.

\footnotetext{
${ }^{1}$ Este estudo faz parte da pesquisa aprovada pelo Comitê de Ética em Pesquisa pela Universidade Federal de Itajubá Campus Itabira, sob registro CAAE 75205517.5.0000.5559 e 75205517.5.3001. 5110. Este projeto é idealizado por um grupo de estudos em Ergonomia Hospitalar e foi apresentado como pesquisa para um Projeto de Iniciação Científica.

${ }^{2}$ Graduado em Engenharia de Saúde e Segurança do Trabalho pela Universidade Federal de Itajubá

${ }^{3}$ Doutor em Educação pela UFMG, Mestre em Engenharia de Produção pela UFMG, Graduado em Fisioterapia pela UFMG. Professor adjunto 3 da Universidade Federal de Itajubá.
}

Trabalho \& Educação | v.28 | n.2 | p.215-230 | maio-ago | 2019 


\section{INTRODUÇÃO}

As transformações ocorridas nos sistemas de produção entre a primeira revolução industrial até as atuais formas de capitalismo globalizado são acompanhadas de mudanças nos modos de viver, trabalhar e de adoecer, afetando todos os níveis e esferas da produção, as relações de competitividade empresarial, a divisão internacional do trabalho, o conteúdo do trabalho e as condições de gestão da saúde no trabalho (ECHTERNACHT, 2008).

Muitos autores têm se dedicado a estudar esse fenômeno, e entre eles (HENNINGTON, 2011) reforça esse pensamento dizendo que o mundo do trabalho, ao longo dos últimos séculos, vem passando por intensas e profundas transformações e sua dinâmica individualista e fragmentadora tem repercutido de maneira contundente na forma de ser e de se fazer o trabalho.

Trabalhar é gerir-se em um meio cuja estrutura produtiva, composta por normas de ordem técnica, organizacional e gerencial, heterodetermina os objetivos do trabalho, seus instrumentos, tempo e espaço. Porém, essa heteroderminação não exclui a mobilização de saberes e valores incorporados nas práticas da atividade, condição para o agir competente em um meio produtivo em constante transformação (ECHTERNACHT, 2008). A atividade de trabalho exige uma constante arbitragem entre o uso de si por si e o uso de si pelos outros, com um debate constante entre as normas antecedentes e as normas inscritas na história do corpo de quem trabalha (SCHWARTZ, 2000). Isso implica em reinterpretar e renormalizar as normas antecedentes, com o objetivo de ajustá-las a si mesmo e à situação de trabalho (MENDES, 2015).

Diante dessas observações, constatou-se que o setor de produção de serviços tem sentido o impacto dessa mudança de cenário, já que quando comparado ao setor primário e secundário tem características que o difere dos demais. Entre elas estão a proximidade entre trabalhador e consumidor como uma das principais características das relações de trabalho desse setor com possibilidades de repercussões específicas nos processos saúde doença. Além disso, a simultaneidade é um elemento fundamental nesse contexto, haja visto que, a produção do serviço ocorre no momento em que ele é consumido, surgindo daí o conceito de inestocabilidade, ou seja, não pode ser estocado e mensurável, tornando-se intangível.

Segundo (MENDES, 2012) tanto o hospital, bem como os outros equipamentos da rede assistencial (Unidades Básicas de Saúde, Unidades de Pronto-atendimento, Centros de Atenção Psicossocial, etc), têm se mostrado como um importante e grave foco de problemas relacionados à Saúde do Trabalhador e Segurança do Trabalho e exigido, de modo crescente, intervenções preventivas. Tais repercussões da atividade de trabalho sobre a saúde têm sido conformadas em processos de desgaste e adoecimento variados, entre os quais destacam-se as LER/DORT, variadas manifestações de adoecimento psíquico e os acidentes de trabalho.

Dando luz à área hospitalar devido ao seu papel essencial na sociedade, vemos que além das características ligadas às atividades dos setores de senviço, existem outras particularidades da esfera hospitalar, já que os trabalhadores inseridos nesse contexto convivem diariamente com vidas humanas em momentos de grande vulnerabilidade, 
experimentando emoções variadas que os expõem a riscos que vão além dos objetiváveis.

Dentro desse contexto, o Centro de Material de Esterilização (CME) é uma unidade, dentro do complexo hospitalar, que presta atendimento indireto ao paciente, tendo como foco principal o processamento de materiais/artigos utilizados no cuidado ao usuário do serviço, em toda a sua diversidade. Acredita-se que seja um ambiente com uma complexidade que favoreça a exposição do trabalhador a riscos, considerando que o sujeito trabalha em contato com fluidos orgânicos, calor e substâncias químicas decorrentes de processos químicos e térmicos de desinfecção e esterilização, em ambiente confinado, sob rotinas monótonas e/ou exaustivas e não raramente insuficiente em recursos materiais e humanos.

A partir daí, despontam-se algumas questões: quais são os elementos necessários para que se efetive as estratégias de regulação adotadas pelos trabalhadores para manutenção da própria saúde e gestão da carga de trabalho? Como o coletivo de trabalho lida com a insuficiência de recursos e materiais? Os valores ali colocados em prática são reconhecidos por todo hospital?

Com base nesse panorama e ambicionando responder às questões propostas, 0 presente estudo tem como objetivo esmiuçar/analisar o funcionamento de um Centro de Material Esterilizado de um hospital do interior de Minas Gerais, evidenciar as estratégias de regulação e gerenciamento da carga de trabalho e observar como é feito o uso de si e do coletivo de trabalho para atender toda demanda a eles apresentada, bem como os infinitos modus operandi, associadas à história de vida de cada trabalhador, os valores ali colocados em prática e sua singularidade, no momento da tomada de decisões.

\section{A GESTÃo dA ATIVIDADE: DESVELANDO AS ESTRATÉGIAS DE REGULAÇÃO}

A atividade de trabalho é ação enigmática singular do humano que produz história. Aquele que trabalha, responde de maneira única a uma demanda, investe todas as dimensões do seu ser (bio-psíquica-social) para gerenciar a distância entre a tarefa e as concretudes da realidade (DANIELLOU, LAVILLE \& TEIGER, 1989; SCHWARTZ \& DURRIVE, 2010).

Trabalhar é escolher as quais riscos se expor e quais responsabilidades assumir. Trabalhar é também gerir-se (SCHWARTZ, 2004), aquele que trabalha escolhe que uso fará de si mesmo, "a partir do momento em que há escolhas a se fazer, isso impõe responsabilidade e precauções importantes” (TRINQUET, 2010, p. 98).

Diversos são os fatores que acometem ao aumento da carga de trabalho do setor de enfermagem, como disposto por Silva et al (2016), observa-se uma elevada carga horária de trabalho, baixa remuneração, relações de poder e hierárquicas extremamente demarcadas, baixa autonomia no processo de trabalho e elevadas exigências para alcançar os objetivos institucionais e melhorar os indicadores produtivos e de qualidade.

A Organização Internacional do Trabalho (OIT) refere que o trabalho deve ser prolífero, remunerado, exercido em condições de segurança e igualdade, sem discriminação e capaz de possibilitar uma vida digna ao profissional (OIT, 1990). Mas, como podemos 
observar no contexto da sociedade capitalista, nem sempre este se configura desta forma, podendo gerar sofrimento e adoecimento.

Diante de tal situação e suas inúmeras formas de compor o ambiente de trabalho, os profissionais inseridos nesse contexto buscam formas de gerir as variabilidades. Essa "estratagema" utilizada pelo sujeito no ato de trabalhar tem como objetivo principal a realização de um trabalho de qualidade, bem como a manutenção da própria saúde no desenvolvimento da atividade laboral.

Como evidenciado por Schwartz (2011, p. 139):

O protocolo é falho, é caracterizado por um vazio de normas, o que significa que ele não consegue antecipar o que vai ser preciso fazer para lidar com a articulação trama e urdidura, assim "cada um tratará esses vazios de normas recorrendo a um universo de recursos pessoais, hierarquizado por seu conjunto de valores do momento".

Como se não bastasse lidar com essas questões, esses profissionais ainda estão submetidos a infortúnios de ordem organizacional, mais precisamente relacionada com a insuficiência de recursos materiais. Para Fajardo Ortiz (1972, p.7), os problemas da gestão da saúde referem-se à "insuficiência de pessoal"; "insuficiência de recursos econômicos e materiais"; "administração antiquadas"; e "locais e equipamentos inadequados".

Análise interessante é feita por Lima; Barbosa (2001, p. 40) que considera a organização hospitalar como "[...] uma empresa de multiprodutos, com vários processos de produção altamente interdependentes, cujos produtos se articulam para a produção de seu principal produto, qual seja, o diagnóstico e tratamento do paciente".

Atentos a isso, analisar a gestão de riscos no trabalho, a assistência ao paciente e a construção da saúde/doença implica acessar a singularidade das experiências individuais e coletivas de reconhecimento e hierarquização dos riscos diante das especificidades das situações produtivas (MENDES; CUNHA, 2017, p. 25).

A melhor maneira de se identificar quais são as ferramentas utilizadas por esses colaboradores para subjugar essas variabilidades e efetivar a realização do trabalho é adentrar no ambiente de trabalho, compreendê-lo e reconhecer as individualidades presentes em cada situação ali apresentada.

\section{Metodologia}

Trata-se de um estudo qualitativo e descritivo com fundamentação teórica e metodológica baseadas na Ergonomia e na Ergologia.

A construção da ação ergonômica é sempre situada no tempo e no espaço, uma vez que cada situação de trabalho tem suas características singulares (variabilidade na execução do trabalho, das suas condições e dos objetivos de produção) e as possibilidades para o seu desenvolvimento e a concretização das transformações são fruto de uma ação social na qual diferentes sujeitos podem ter uma contribuição significativa. A contribuição da ergonomia está precisamente em reincorporar os sujeitos do trabalho nas suas análises e, esse interesse central pela atividade exige um esforço de "observar o trabalho com uma lupa" (SCHWARTZ \& DURRIVE, 2010, p. 39). Segundo Silva et al. (2015, p. 90), não se pode negligenciar que há um conjunto de 
fatores que, conjugados, permitem que cada um faça a gestão daquelas infidelidades de maneira a produzir os resultados esperados.

Colocadas e debatidas essas questões centrais que compõem um conjunto teórico ergonômico, optou-se também pelo aprofundamento epistemológico da Ergologia. A ergologia também se apropria e aprofunda as noções da ergonomia sobre a diferença entre prescrito e real e as variabilidades presentes nas diversas situações de trabalho.

A atividade é, portanto, uma noção que deve ser associada à dinâmica da própria vida (CANGUILHEM, 2010).

\section{Procedimento de coleta de dados}

Inicialmente foi acordado com o Diretor Técnico do hospital todas as características da pesquisa, bem como os detalhes sobre as visitas técnicas e critérios de postura e confidencialidade. Posteriormente, foi realizada uma reunião com a Responsável Técnica do setor, em que foi apresentado a ela e logo em seguida aos colaboradores, o Termo de Consentimento Livre e Esclarecido, assegurando o total conhecimento e voluntariedade dos envolvidos. Somente após essa etapa inicial é que de fato se iniciou a entrada no setor e a coleta de dados. Além disso, o estudo foi aprovado em 2 comitês de ética em pesquisa (proponente e coparticipante), por meio dos Certificados de Aprovação para Apreciação Ética - CAAE 75205517.5.0000.5559 e 75205517.5.3001.5110, respectivamente.

Logo após toda a formalização da parte burocrática, foram realizadas observações sistemáticas por meio do acompanhamento diário do setor analisado, conhecendo assim todo o processo de trabalho, fluxo de serviço e características do ambiente.

As coletas foram feitas entre os meses de março a junho de 2018 e, em um primeiro momento, foi coletado através de um questionário semiestruturado informações sobre aspectos sócio demográficos dos participantes, tais como, idade, sexo, jornada de trabalho, setor de trabalho, tempo de serviço e escolaridade. A partir daí, através de um estudo com caráter descritivo e exploratório, foi possível compreender as diversas situações vividas no ambiente, já que a coleta de dados se deu no ambiente natural, por meio do acompanhamento do dia a dia de trabalho, transcrição das verbalizações dos trabalhadores envolvidos, confrontação simultânea em determinadas questões e, posteriormente, ordenação e estudo dos pontos que apresentaram maior relevância.

A posteriori, após uma série de visitas e certo contato com os funcionários, foram realizadas indagações voltadas para a rotina de trabalho, tentando compreender o fluxo do processo e a base da rotina do local. Questões acerca de como é realizada a lavagem e o preparo do material cirúrgico; quais os procedimentos são realizados na esterilização e armazenamento do material cirúrgico e as dificuldades e facilidades no seu cotidiano de trabalho, ao desenvolver as atividades inerentes ao processo de esterilização.

\section{Características do hospital}

O hospital estudado se mantém por meio de recursos governamentais e por meio do Pro Hosp do governo estadual. É referência microrregional em traumatologia, maternidade e de hemodiálise para uma população estimada em 300 mil habitantes, 
pois, além de atender os habitantes da cidade onde está situado, presta atendimentos aos habitantes das cidades da região.

No início do ano de 2016, esse hospital passou a atender toda a demanda advinda do processo de transformação do outro hospital da cidade em atendimento à saúde, dado que, a população que utiliza plano de saúde passaria a ser atendida somente em um hospital e o mesmo ainda não possuía atendimento emergencial. No intuito de atender a demanda da população, que ficaria carente desse tipo de atendimento, o pronto atendimento (PAC) foi aberto em uma área antiga do hospital, sendo dessa forma um local provisório, mas que atualmente consegue atender a população.

A partir das características iniciais levantadas sobre a situação atual do hospital, ficou acertado que aquele seria um local que traria grandes contribuições para ambos os lados, haja vista que, os pesquisadores/universidade teriam uma área gigantesca e interessantíssima para produção de conhecimento, e a instituição objeto de estudo poderia colher os frutos dessa parceria aumentando a satisfação dos funcionários, melhorando as condições de trabalho e, consequentemente, aumentando a produtividade dando ênfase à saúde dos colaboradores que ali atuam.

Como no hospital existem diversos setores, após uma análise detalhada de todos eles, elegeu-se o Centro de Material Esterilizado (CME) para o foco da pesquisa, em razão de sua centralidade, complexidade, prestação de atendimento a todos os setores do hospital, pouco reconhecimento do valor do trabalho ali prestado por outros funcionários da instituição, além do papel da coletividade na gestão da carga de trabalho.

Esse setor é composto por 27 profissionais, todas do sexo feminino e seu funcionamento se dá 24 horas por dia, em 2 turnos de trabalho e 1 turno com horário administrativo, válido somente para as duas enfermeiras chefe.

Essa unidade funcional de apoio técnico é responsável pelo processamento de produtos para a saúde em serviços de saúde. Esse setor atua visando à prevenção de infecções, mesmo que indiretamente, articulando ciência, segurança e qualidade, por meio da equipe de enfermagem.

Todos os materiais não descartáveis utilizados no hospital para atendimento aos pacientes passam pelo local, já que o instrumental utilizado pelo paciente deve ser processado adequadamente a fim de que esse material não se torne uma fonte de contaminação e transmissão de microrganismos. Abaixo temos um esquema do ciclo de utilização dos materiais e as etapas de processamento dentro da unidade especializada.

FIGURA 1- Dinâmica Centro de Material Esterilizado 


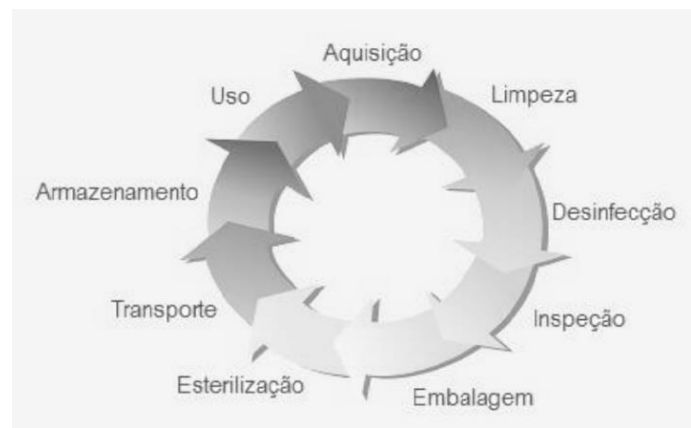

Fonte: Imagem retirada da internet. ${ }^{4}$

Além do atendimento ao hospital, o CME faz o processamento dos materiais utilizados pelo Pronto Socorro, unidade que fica em anexo ao hospital, o que demanda aos funcionários uma exata caracterização da origem dos materiais chegados ao expurgo, para que logo após finalizado o processo de esterilização, esse conteúdo volte ao seu local de origem para não causar maiores transtornos.

A análise dos números fornecidos pela instituição mostra a importância da unidade e a carga de trabalho a que estes trabalhadores estão submetidos. No ano de 2017 foram realizados aproximadamente 20 mil atendimentos pelo hospital, derivando daí algo em torno de 800 cirurgias/mês, demonstrando a importância do centro de processamento para o correto funcionamento desta engrenagem.

Como visto, além de ser um ambiente de trabalho que requer atenção especial devido a sua complexidade, a grande demanda por utensílios para atender aos diversos setores, bem como alguns problemas causados por insuficiência de recursos materiais e limitações do espaço físico podem agravar ainda mais esse contexto. Para que todo o processo seja realizado com o grau de êxito esperado, mesmo diante das inúmeras variabilidades que se apresentam cotidianamente, os trabalhadores traçam estratégias de regulação para manter a eficiência no trabalho e para manutenção da própria saúde, sendo o coletivo de trabalho peça chave para o cumprimento do esperado.

\section{ObJeto de ESTUdo: enfERMEIROS, TÉcNicos EM ENFERMAGEM E AUXILIARES}

O trabalho do enfermeiro do CME é bastante complexo, pois acumula características técnico-assistenciais, como a gestão de pessoas e da área física, atividades privativas ao setor, manuseio de novas tecnologias, além da capacidade de visualizar as necessidades de outras áreas que dependem do seu trabalho (TAUBE; ZAGONEL; MEIER, 2007).

O perfil dos entrevistados obedece a algumas características, como: faixa etária variando entre 23 e 65 anos, com tempo médio de prestação de serviços no setor em até 5 anos, público exclusivamente feminino e com funções variando entre enfermeiras, técnicas em enfermagem e auxiliares.

A população é composta por 27 pessoas, sendo que no decorrer da pesquisa 1 funcionária estava afastada por motivos de saúde, não participando do processo. 0 regime de trabalho é de $12 \times 36$ (doze horas de trabalho por 36 horas de descanso), com o primeiro turno iniciando às 7 da manhã e finalizando às 19 horas. Para a

\footnotetext{
${ }^{4}$ Disponível em: http://www2.ebserh.gov.br/documents/147715/0/central+de+material+e+esterilização. 
responsável técnica da área e uma outra enfermeira que faz o acompanhamento da unidade, o horário obedece ao turno administrativo.

As funções a serem realizadas pelas funcionárias do CME variam de acordo com a escala de trabalho. Foi instalada uma política de rotatividade no local, dividindo o centro nos seguintes setores: expurgo, área de preparo, recepção/embalagens e arsenal. Elas se revezam entre essas áreas, divididas em pequenos grupos pré-definidos e caso seja necessário, há um remanejamento pontual para suprir determinada demanda.

Constatado isso e visto as diversas tarefas que os trabalhadores do setor podem ter que desempenhar em seu ato laboral, um correto entendimento do fluxo de trabalho e um maior detalhamento do setor estudado se fez necessário para auxiliar nessa compreensão.

\section{Sistemática de funcionamento do Centro de Material Esterilizado}

Como dito, o Centro de Material esterilizado pode ser divido em 3 áreas, sendo essas delimitadas por barreiras físicas e com características distintas.

Expurgo: $\mathrm{A}$ área de expurgo do CME é o local onde é feita a recepção de todo o material contaminado e sujo da instituição, para limpeza, desinfecção e esterilização. É fundamental que o material seja selecionado e desinfetado imediatamente após o seu recebimento na área de expurgo, evitando o acúmulo dos mesmos e, consequentemente, que matérias orgânicas fiquem aderidas, tornando mais difícil a sua limpeza.

Outro ponto importante do processo é que essa limpeza seja realizada antes do processo de esterilização, uma vez que a sujeira e matéria orgânica protegem os micro-organismos, impedindo que o agente esterilizante aja sobre ele.

Nessa área, normalmente 2 funcionárias fazem o trabalho diariamente, sempre munidas dos Equipamento de Proteção Individual (EPI) pertinentes como descrito no mapa de risco do local. Basicamente são os óculos, máscaras, botas, luvas e avental impermeável e protetor para ruído. Devido ao tipo de trabalho que é desenvolvido na área, o funcionário utiliza também touca descartável, óculos de acrílico e luvas de borracha antiderrapante para impedir que o funcionário entre em contato direto com material ou objeto contaminado.

O material é recebido através de uma bancada na porta do expurgo e acondicionado em uma mesa de apoio para conferência da quantidade e destino de origem. Uma planilha deve ser preenchida com todos os dados, responsável pela entrega e pelo recebimento e a data. Os horários de entrega são definidos previamente sendo que apenas o Centro Cirúrgico e Hemodiálise tem permissão para efetuar a entrega dos materiais assim que utilizam, devido a urgência em colocá-los prontos para o uso o mais rápido possível. A padronização de horários no recebimento do material é importante para organizar a dinâmica do trabalho e favorecer o funcionário no desenvolvimento das rotinas técnicas.

Devido à grande diversidade de instrumental e material recebidos em um CME, a codificação dos mesmos é um processo que ajuda no controle, principalmente quando se trata de caixas de instrumentais cirúrgicos. Esta codificação é feita através de cores 
pintadas em uma pequena parte de cada instrumental e caixa para que os materiais sempre retornem para o seu setor de origem.

A área do expurgo requer do funcionário bastante atenção e responsabilidade, pois as atividades ali desenvolvidas são o ponto de partida de todo o trabalho realizado no CME. Compete ao técnico em enfermagem ou auxiliar realizar as atividades de acordo com as rotinas técnicas, sempre sob a supervisão da Responsável Técnica do setor.

Área de Preparo: Esta área tem como objetivo proporcionar aos profissionais que utilizarão o material esterilizado o conforto de ter nas mãos o material completo, na sequência necessária e em perfeitas condições de uso. É nesta parte que se concentram o maior número de atividades do setor, juntamente com a maior demanda por funcionários.

As roupas que chegam da lavanderia passam pelo processo de separação e dobragem, todas com uma metodologia específica de acordo com sua função. Sua separação e acondicionamento em pacotes denominados "campos" são realizados normalmente por 3 funcionárias, sendo que uma quarta funcionária posicionada estrategicamente em frente às autoclaves registra tudo em planilhas, etiqueta todos os pacotes e abastece as máquinas com o material a ser esterilizado.

Outra funcionária fica posicionada na bancada ao lado, fazendo a inspeção visual de todos os equipamentos respiratórios. Esta bancada é equipada com uma lupa e luz especial e o trabalho ali realizado requer concentração e uma apurada vistoria. É aqui também que são montadas as caixas com instrumental cirúrgico e material implantado, procedimento este que só pode ser realizado pelas enfermeiras. Quando o processo de inspeção e montagem dos kits é finalizado, tudo tem que ser embalado em uma manta adequada chamada de SSMMS5 e colocado na autoclave para esterilização com o programa adequado.

Arsenal: Também chamado de local de armazenamento, é aqui onde os produtos saídos da autoclave e prontos para uso são acondicionados. A responsável técnica do setor confere a lista de cirurgias programadas para o dia seguinte, e passa para a funcionária que estiver alocada na área no dia separar e realizar a entrega desses materiais para os setores. Todo esse processo tem horários pré-definidos e são realizados até às 10 da manhã todos os dias, exceto para bloco cirúrgico e hemodiálise, que não tem restrição de horários para fazer requisição.

Figura 2- Fluxo dos materiais ao entrar no CME

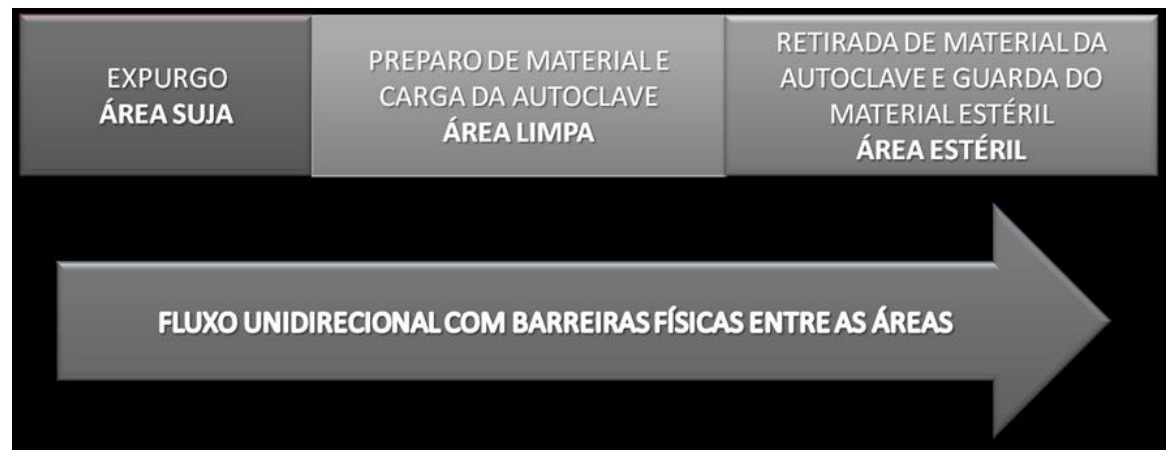

\footnotetext{
${ }^{5}$ Manta com 5 camadas $100 \%$ Polipropileno, composta por três camadas externa de Spunbond e duas camadas interna de Meltblown unidas através de processo de calandrag témica, com isenção de produtos químicos na sua fabricação e porosidade controlada.
} 
FIGURA 3- Croqui do centro de Material Esterilizado

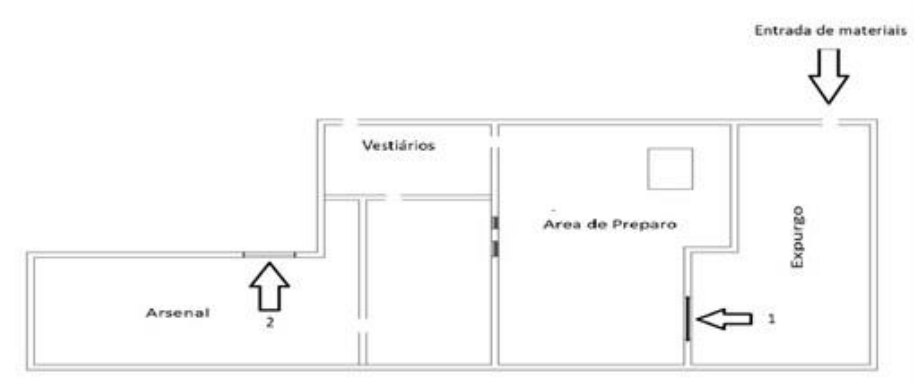

Fonte: Próprio autor.

\section{Prescrito X ReAL: Dificuldades impostas PELO trabalHo}

O coletivo de trabalho é elemento fundamental na construção das boas práticas de segurança no trabalho, uma vez que a comunicação entre eles muitas vezes se dá apenas pelo modo de olhar, determinado posicionamento no ambiente de trabalho e outras características que somente quem está inserido no contexto consegue entender.

Atentos a isto, os profissionais do setor no decorrer da execução de suas atividades lidam a todo instante com demandas das mais variadas formas. Durante a realização da pesquisa, diversas situações se apresentaram, e utilizando a ferramenta de confrontação simultânea, as verbalizações foram fundamentais para entender a situação.

Em uma delas, quando questionada sobre uma eventual necessidade de suprir a demanda de um determinado instrumental, mesmo já reservados para o dia, obteve-se a seguinte resposta:

"Se aparecer uma emergência e todos os kits para este tipo de cirurgia estiverem reservados para o dia, a gente pega a caixa da cirurgia que for mais tarde, envia para o bloco e depois busca correndo para esterilizar de novo".

Em outra situação presenciada, uma das máquinas de esterilização apresentou problemas e como o local conta com apenas duas, esse fato ocasionou excesso de demanda para a outra. Tentando manter o estoque do arsenal apto a atender as possíveis solicitações do hospital, o corpo técnico do local reagrupou os materiais e, de acordo com o levantamento feito pela técnica que monitorava o estoque no dia, ficou definido que a prioridade seria os kits para operações de ortopedia.

"Eu estou fechando a ortopedia (caixas) que é o que tem mais necessidade. Quando a outra máquina estiver pronta, a gente coloca os materiais que ficaram para trás".

Todas essas situações ilustradas acima demonstram que o trabalho vai muito além do planejado. O cronograma de realização das tarefas do dia, a ordem e forma de execução das atividades e todos os outros fatores que compõem o ato de trabalho são

\footnotetext{
${ }^{6}$ Disponível em: http://sinnapse.blogspot.com/2012/06/perioperatorio-central-de-material.html
} 
previamente decididos, mas a sua aplicação daquela forma ou não acontece no momento em que o trabalho acontece, sendo o sujeito à frente daquela tarefa 0 responsável pela escolha da melhor maneira de gerir a situação.

Durante a realização do estudo, diversos foram os fatores observados que intensificam a carga de trabalho e geraram constrangimentos para os atores ali envolvidos. Por meio do acompanhamento das atividades, observações do pesquisador e, principalmente, verbalizações dos funcionários, verificou-se alguns elementos que se destacaram dos demais. Entre eles estão:

- Insuficiência de recursos financeiros para modernização da unidade;

- Necessidade de automatização dos setores, facilitando o registro de entrada e saída de utensílios, diminuindo o retrabalho;

- Ausência de um plano de manutenção preditiva para os equipamentos, principalmente as autoclaves, evitando sobrecarga de trabalho e estresse quando ocorrer algum problema;

- Ausência de um programa de treinamento e/ou reciclagem dos funcionários, visando aprimorar a parte técnica e diminuir os erros causados pelo automatismo.

\section{Discussão}

De acordo com Winnicott (2011), o trabalho possibilita ao indivíduo um fazer criativo no mundo, uma forma de expressão pessoal e social, agregado de valores intrínsecos, que gera construção e transformações, em dupla via, quando realizado em condições favoráveis.

Atualmente, a informação e a comunicação se tornaram elementos fundamentais à produção. Houve, também, uma apropriação e exploração de capacidades humanas no mundo do trabalho como a criatividade, a capacidade organizativa e de cooperação, a comunicação e a habilidade dos trabalhadores na resolução de problemas que passam a ser valorizadas e imperativas no novo ideário produtivo (ANTUNES, 1999).

Em um dos locais que faz parte da divisão externa do Centro de Material Esterilizado conhecido como Arsenal, ficou evidente a necessidade do trabalhador exercer ao máximo sua capacidade de organização e, sobretudo, de cooperação para atender as expectativas que todo hospital deposita no local. Este ambiente é o local de retirada dos materiais prontos para uso e uma funcionária por turno fica responsável pela tarefa. $O$ que acontece é que a organização das caixas ortopédicas que são mais pesadas nas prateleiras de baixo, e o atendimento emergencial para setores que podem solicitar material a qualquer hora, como Bloco Cirúrgico e Hemodiálise, demandam uma atenção maior do colaborador, que além de gerir todo estoque e organizá-lo de maneira menos penosa, precisa ficar atento a possíveis desabastecimento decorrentes de pedidos aleatórios.

Esse local, assim como todo CME busca se regular e foge ao prescrito para dar conta da demanda a eles apresentada, e os profissionais ali presentes se envolvem por inteiro, fazendo daquilo muito mais que uma mera execução da tarefa, se envolvem por inteiro, se sentem como fazendo parte do meio.

Como dito por Mendes (2014), o ato de trabalhar não se restringe a um uso heterodeterminado de homens e mulheres pelos gestores dos sistemas de produção, 
mas a uma experiência de si mesmo, numa relação com a própria história. A atividade humana de trabalho exige uma constante arbitragem entre o uso de si por si mesmo e o uso de si por outros, num debate permanente entre as "normas antecedentes" e as normas internas inscritas na história do corpo de quem trabalha.

A preocupação com eficácia e racionalidade comumente presente nas organizações se expressa no que os ergonomistas chamam de "trabalho prescrito", ou seja, "o trabalho que foi determinado, 'cientificamente pensado' por pessoas que fizeram cálculos de tempo, de eficácia, portanto, que estudaram tudo, de fato, detalhadamente" (SCHWARTZ, 2010d, p. 40). Visando à menor perda de tempo, bem como encontrar a maneira ótima para realização, o trabalho prescrito é definido de modo externo e imposto aos trabalhadores. No entanto, conforme Duraffourg, Duc e Durrive (2010, p. 70), o prescrito tende a se dissolver, ou seja, pode estar "[...] formalizado nos livros sobre a organização, ele pode ser afixado num mural, ser objeto de esquemas, modelos, razões. Ele é registrável, é visível, pode ser verbalizado".

Por outro lado, tudo o que é da ordem do real é dificilmente visto e expresso. Quantos trabalhadores dizem: 'eu estou acostumado', e não conseguem verbalizar sua maneira de fazer! Em razão disso, a Ergologia privilegia o conceito de "normas antecedentes", que engloba o conceito ergonômico de trabalho prescrito (TELLES e ALVAREZ, 2004).

Conforme Vieira-Júnior e Santos (2012, p. 94), o conceito de "normas antecedentes"

[...] é mais abrangente que o seu precursor [trabalho prescrito], por incorporar várias dimensões presentes nas situações de trabalho, como: a) as aquisições de inteligência do trabalhador; b) as experiências coletivas; c) o saber-fazer; d) as construções históricas analisadas como patrimônio cultural e científico; e) a dimensão dos valores, que transcende a questão monetária e se posiciona na esfera do político, dos debates e dos conflitos que findam por compor o caráter híbrido desse conceito.

As normas antecedentes referem-se, portanto, ao modo como experiências coletivas produzem normas situadas num tempo-espaço laboral, considerando-se ainda a parcela de singularidade de cada trabalhador que compõe o grupo, uma vez que estão subjacentes nelas valores coletivos e individuais (SCHWARTZ, DUC e DURRIVE, 2010d). O que leva a outro conceito relevante, o de "valores", que, na Ergologia, referese ao [...] peso que se atribui mais ou menos às coisas; uma hierarquia, uma categorização própria a cada um a propósito do que se estima, prefere, ou pelo contrário se negligencia, rejeita. Em certa medida, é a tentativa de cada um de ter uma maestria sobre o meio no qual se encontra (exemplo: um escritório personalizado). $O$ indivíduo não inventa sozinho a prescrição e nem os seus valores, mas retrabalha incessantemente os que o meio lhe propõe (DURRIVE e SCHWARTZ, 2008, p. 27).

Diversos são os momentos em que o prescrito é deixado de lado e a atividade real aflora, mostrando as estratégias adotadas pelo funcionário naquele exato momento. Como exemplo, temos a recomendação a respeito do descarte dos sacos plásticos utilizados para embalar a rouparia vinda da lavanderia. Segundo a prescrição, esses sacos devem ser rasgados e descartados imediatamente na lixeira, já que vieram de um local em contato com materiais não esterilizados. O que acontece é que o local de descarte é afastado do local onde é feita a dobragem das roupas e, para evitar perda de tempo, as funcionárias acumulam uma certa quantidade desse material nas prateleiras e, assim que julgam necessário, fazem o descarte do mesmo. Vale observar que não há risco de contaminação uma vez que os materiais da prateleira terão que 
passar ainda pelo processo de esterilização, mas já fica evidenciado essa lacuna entre a tarefa e a atividade.

Em um segundo momento, quando houve um problema técnico em uma das autoclaves, pôde-se observar com bastante clareza a regulação que a enfermeira chefe faz para gerenciar a equipe e consequentemente manter o padrão de atendimento da unidade. Assim que foi detectada a disfunção no equipamento, foi solicitado ao arsenal um levantamento do que estava armazenado e em consonância com a agenda de cirurgias do dia, foi feito um rearranjo dos materiais que seriam esterilizados, deixando somente os itens com maior urgência na fila da outra autoclave.

Esse ato de remanejar os itens pode parecer simples, mas só é bem feito e produz efeitos benéficos devido a experiência da equipe em questão e o valor no trabalho, caso contrário o impacto seria sentido por todo hospital.

Pelos dados coletados, observou-se baixa rotatividade na unidade estudada, confirmando as verbalizações feitas pelos funcionários sobre a satisfação em trabalhar naquele local. Em uma das ocasiões, foi feita a seguinte afirmativa por uma técnica:

"Eu gosto muito do CME, já trabalhei em outros setores, mas aqui é o que eu mais gostei. Tenho até vontade de fazer uma pós um dia".

Pôde-se observar que o baixo índice de turnover no local analisado favoreceu o estreitamente dos laços no ambiente e, por consequência, tornou o ambiente de trabalho menos impessoal e de mais fácil lida com os desafios diários.

Ao mesmo tempo, essa satisfação em trabalhar no local contrasta com a falta de reconhecimento do restante do hospital sobre importância do trabalho desempenhado por estas profissionais. Quando questionada sobre a visão dos funcionários de outros setores sobre as atividades ali praticadas, a fala de uma delas foi categórica:

"Cruz credo! Eu é que não quero ir pra lá lavar vasilha e dobrar roupa".

Conforme Silva e Aguiar (2008), o desprestígio da execução deste trabalho pode estar ligado ao fato do desconhecimento deste setor pelas unidades consumidoras.

Vale ressaltar que, mesmo com essa hipossuficiência gratular, o trabalho desempenhado por todas as profissionais do setor é sempre de alcançar a excelência em todos os momentos, sendo a tomada de decisões baseada nos valores e ética ali colocados em prática almejando o objetivo maior: prestar um atendimento de qualidade ao paciente, mesmo que de forma indireta.

Daí emerge ainda as noções de "Entidades Coletivas Relativamente Pertinentes" e de "saberes investidos". A primeira é utilizada para diferenciar as entidades coletivas daquelas definidas por organogramas ou por lugares, postos e responsabilidades, remetendo, em vez disso, aos coletivos dentro de um "campo ergológico", ou seja, que diz respeito à atividade humana, uma vez que suas fronteiras não são predefinidas, mas sim assentadas pela atividade num dado momento, como "sinfonias sem maestro" (SCHWARTZ, 2010a). A noção de "saberes investidos", por sua vez, refere-se aos saberes que ocorrem em aderência, em capilaridade com a gestão de todas as situações de trabalho, e que são adquiridos nas trajetórias individuais, coletivas e singulares (SCHWARTZ, 2010b). Ou seja, são os saberes diversos constituídos e retrabalhados coletiva e individualmente nas atividades. 
Para que isso realmente se efetive e se desdobre em êxito na atividade realizada, várias são as competências que devem ser colocadas em prática por essas funcionárias. Segundo Scherer et al. (2016, p.95), cada gestão irá variar de indivíduo para indivíduo, visto que, por meio de suas histórias, valores e a atividade ao qual está ou já esteve exposto, cada indivíduo desenvolve uma forma de competência, tais competências que são ferramentas cognitivas afiadas para desempenhar todas as funções demandadas em seu dia a dia com qualidade e sensibilidade, o que determina um maior 'uso de si'.

Essa percepção única e individual dos momentos ali vividos é o que torna a atividade singular, situando-a naquele tempo e espaço e exigindo do profissional habilidades que muitas vezes foram desenvolvidas sem que ele mesmo percebesse. Esse emaranhado de histórias, valores e competências é o que faz, por exemplo, os funcionários do hospital realizarem empréstimos de materiais para outros hospitais, mesmo que isso gere transtornos para eles, já que muitas vezes essas outras unidades não possuem unidades de esterilização própria, aumentando o trabalho dos mesmos. Essas e outras situações presenciadas são fundamentais para compreender a construção do ato de trabalhar, e essa gestão de si por si e de si pelos outros é característica fundamental no processo.

Reconhecer que existe uma lacuna entre a tarefa prescrita e a atividade real, enxergar os valores dimensionáveis e não dimensionáveis que movem esses trabalhadores e acima de tudo compreender que todos esses aspectos influenciam na carga de trabalho a que estão submetidos é fundamental para a proposição de melhorias no ambiente de trabalho.

Posto isto, o denominador comum que se chega ao analisar a unidade de esterilização e juntamente com ela os profissionais ali inseridos, é de que prestar um serviço de qualidade, conseguir gerir de maneira satisfatória a própria saúde e a saúde dos demais ali presentes sempre que possível para evitar distúrbios, bem como solucionar as diversas problemáticas do cotidiano visando dar continuidade ao fluxo de trabalho é o que todos esperam alcançar.

\section{Considerações Finais}

Conhecer a fundo a realidade de trabalho em que os colaboradores estão inseridos é fundamental para a compreensão de como é feito o uso de si por si mesmo e o uso de si por outros, na construção do coletivo de trabalho.

Entender como é o processo de gestão da unidade, maneiras utilizadas para superar as adversidades inerentes ao ato de trabalhar, bem como a identificação das estratégias empregadas para dar conta do que é demandado foi de suma importância para a concepção deste estudo.

A proposição de melhorias no ambiente de trabalho se dá de maneira muito mais eficaz quando o sujeito à frente da atividade é ouvido, e é através dos seus saberes que são gerados espaços de debate para a construção de melhorias.

A utilização da Análise Ergonômica do Trabalho juntamente com as ferramentas da Ergologia foi fundamental para a compreensão da situação de trabalho analisada, fazendo emergir a atividade, os constrangimentos e suas (im) possibilidades de gestão, 
revelando as estratégias até então construídas, e demonstrando a importância do coletivo de trabalho ali instalado.

\section{REFERÊNCIAS}

CANGUILHEM, G. O normal e o patológico. 6 ed. Rio de Janeiro: Forense, 2010.

DANIELLOU, F., LAVILLE, A. \& TEIGER, C. (1989). Ficção e realidade do trabalho operário. Revista Brasileira de Saúde Ocupacional, 17(68), 7-13.

DURAFFOURG, J.; DUC, M.; DURRIVE, L. O trabalho e o ponto de vista da atividade. In: SCHWARTZ, Y.; DURRIVE, L. (Org.). Trabalho \& Ergologia: conversas sobre a atividade humana. 2. ed. Niterói: EdUFF, 2010. 47-87 p.

DURRIVE, L.; SCHWARTZ, Y. Revisões temáticas: glossário da Ergologia. Laboreal, v. 4, n. 1, p. 23-28, 2008.

ECHTERNACHT, E. Atividade humana e gestão da saúde no trabalho: elementos para reflexão a partir da abordagem ergológica. Laboreal, v.4, n.1, p. 46-55, 2008.

FAJARDO ORTIZ, G. Teoría y práctica de la administracion de la atencion medica y de hospitales. México: La Prensa Médica Mexicana, 1972.

HENNINGTON, E.A. (2011). Entre o criativo e o precário: reflexões sobre constrangimentos e possibilidades do trabalhador da saúde em tempos líquidos. In: C.M. Gomez, J.M.H Machado \& P.G.L. Pena, Saúde do Trabalhador na Sociedade Brasileira Contemporânea. Rio de Janeiro: Fiocruz.

LIMA, S. M. L.; BARBOSA, P. R. Planejamento e inovação gerencial em um hospital público: o caso do Hospital Municipal Salgado Filho (SMS/RJ). Revista de Administração Pública, Rio de Janeiro, v. 35, n.3, p. 37-76, maio/jun. 2001.

MENDES, Davidson Passos et al. Do prescrito ao real: a gestão individual e coletiva dos trabalhadores de enfermagem frente ao risco de acidente de trabalho. Gest. Prod. [online]. 2012, vol.19, n.4, pp. 885-892. ISSN 0104-530X.

MENDES, Davidson Passos et al. O agir competente como estratégia de gestão do risco de violência no trabalho: o ponto de vista da atividade humana de trabalho dos técnicos de enfermagem de uma instituição pública psiquiátrica. p.15-21, 2014.

MENDES, D. P.; CUNHA, D.M. . A gestão coletiva do risco de violência e da assistência em uma unidade hospitalar de emergência psiquiátrica: os ingredientes da competência em crônicas da atividade. Ergologia, v. 17, p. 23-52, 2017.

OIT: Organización Internacional Del Trabajo. In: Conferencia internacional del trabajo. El Trabajo Nocturno. Ginebra: OIT , 1990.

SCHERER, Magda Duarte dos Anjos et al. Aumento das cargas de trabalho em técnicos de enfermagem na atenção primária à saúde no Brasil.Trab. educ. saúde, Rio de Janeiro , v. 14 , supl. 1, p. 89104, nov. 2016. Disponível em: <http://www.scielo.br/scielo.php?script=sci_arttext\&pid=S198177462016000400089\&lng=en\&nrm=iso >. Acesso em: 23 março 2018.

SCHWARTZ, Y. A comunidade científica ampliada e o regime de produção de saberes. Revista Trabalho e Educação, jul-dez, n.7, p. 38-46, 2000.

SCHWARTZ, Y. Circulações, dramáticas, eficácias da atividade industriosa. Trabalho, Educação e Saúde, Rio de Janeiro, v. 2 (1): 33-55, 2004.

SCHWARTZ, Y., \& Durrive, L. (Orgs.) (2010). Trabalho e ergologia: conversas sobre a atividade humana (2a ed). Niterói: Editora da UFF.

SCHWARTZ, Y. A dimensão coletiva do trabalho e as Entidades Coletivas Relativamente Pertinentes (ECRP). In: SCHWARTZ, Y.; DURRIVE, L. (Org.). Trabalho \& Ergologia: conversas sobre a atividade humana. 2. ed. Niterói: EdUFF, 2010a. 147-164 p. 
SCHWARTZ, Y.; DUC, M.; DURRIVE, L. A linguagem em trabalho. In: SCHWARTZ, Y.; DURRIVE, L. (Org.). Trabalho \& Ergologia: conversas sobre a atividade humana. 2. ed. Niterói: EdUFF, 2010b. 131-148 p.

SCHWARTZ, Y. Reflexão em torno de um exemplo de trabalho operário. In: SCHWARTZ, Y.; DURRIVE, L. (Org.). Trabalho \& Ergologia: conversas sobre a atividade humana. 2. ed. Niterói: EdUFF, 2010d. 37-46 p.

SCHWARTZ, Y. (2011). Manifesto por um ergoengajamento. In: P. Bendassolli, L. Sobbol (Orgs.). Clínicas do trabalho (pp. 132-166). São Paulo: Editora Atlas.

SILVA, Silmar Maria et al. Temáticas investigadas pelo Grupo de Estudos sobre a Saúde do Trabalhador de Enfermagem e Saúde [Research topics of the Study Group on Occupatonal Health of Nursing and Health Personnel]. Revista Enfermagem UERJ, [S.I.], v. 24, n. 5, p. e22974, out. 2016. ISSN 0104-3552. Disponível em: <http://www.e-publicacoes.uerj.br/index.php/enfermagemuerj/article/view/22974/20184>. Acesso em: 04 jun. 2018.

SILVA, A.C; AGUIAR, B.G.C. O enfermeiro na central de material e esterilização: uma visão das unidades consumidoras. Rev Enferm UERJ. 2008 Jul-Set; 16(3):377-81.

TAUBE, S.A.M.; ZAGONEL, I.P.S.; MEIER. M.J. Um marco conceitual ao trabalho da enfermagem na central de material e esterilização. Rev Cogitare Enferm. 2005 Mai-Ago;10(2):76-83.

TELLES, A. L.; ALVAREZ, D. Interfaces ergonomia-ergologia: uma discussão sobre trabalho prescrito e normas antecedentes. In: FIGUEIREDO, M. et al. (Org.). Labirintos do trabalho: interrogações e olhares sobre o trabalho vivo. Rio de Janeiro: DP\&A, 2004. 63-90 p.

TRINQUET, P. (2010). Trabalho e Educação. Revista HISTEDBR On-line, número especial, 93-113.

VIEIRA-JÚNIOR, P. R.; SANTOS, E. H. A gênese da perspectiva ergológica: cenário de construção e conceitos derivados. Trabalho \& Educação, Belo Horizonte, v. 21, n. 1, p. 83-100, jan./abr.2012.

WINNICOTT, D, W. Tudo Começa em Casa. São Paulo: Martins Fontes, 2011.

Data da submissão: 01/04/2019

Data da aprovação: 30/04/2019 